\title{
PENGARUH RASIO EPOKSI/AMPAS TEBU DAN PERLAKUAN ALKALI PADA AMPAS TEBU TERHADAP KEKUATAN BENTUR KOMPOSIT PARTIKEL EPOKSI BERPENGISI SERAT AMPAS TEBU
}

\author{
Akhmad Nadji Shabiri*, Rizky Salaam Ritonga, M. Hendra S. Ginting \\ Departemen Teknik Kimia, Fakultas Teknik,Universitas Sumatera Utara, \\ Jl. Almamater Kampus USU Medan 20155, Indonesia \\ *Email : dr.n_najee@yahoo.com
}

\begin{abstract}
Abstrak
Penelitian ini bertujuan untuk mengetahui pengaruh perlakuan alkali serat dan komposisi terhadap sifat kekuatan bentur komposit epoksi berpengisi serat ampas tebu. Komposit dibuat dengan metode hand lay up (menggunakan cetakan terbuka) dengan mencampurkan epoksi dan pengisi serat ampas tebu dengan variasi rasio fraksi volume, 100/0, 70/30, 60/40, 50/50 (v/v) dan konsentrasi larutan $\mathrm{NaOH}$ dalam perlakuan alkali $0 \%, 1 \%, 2 \%$, dan $3 \%$. Sifat mekanik yang diuji yaitu kekuatan bentur, dan di analisa menggunakan analisa SEM. Hasil yang diperoleh dari penelitian ini adalah nilai kekuatan bentur maksimum dari komposit berada pada perbandingan komposisi 70:30 dengan konsentrasi $\mathrm{NaOH} 2 \%$ sebesar $8,005 \mathrm{~kJ} / \mathrm{m}^{2}$.
\end{abstract}

Kata kunci : ampas tebu, epoksi, kekuatan bentur, perlakuan alkali

\begin{abstract}
This study was aimed to determine the effect of alkali treatment and fiber composition on the impact strength properties of epoxy composites filled with bagasse fiber. Composites are made by hand layup method by mixing epoxy and bagasse fiber with variation of volume ratio between matrix and filler are 100/0, 70/30, 60/40, and 50/50 (v/ v) and the concentration of $\mathrm{NaOH}$ slolution in the alkali treatment are $0 \%, 1 \%, 2 \%$, and $3 \%$. Mechanical propertie tested was impact strengthand analized by SEM analysis. The results obtained from this study was the maximum impact strength value obtained of the composite was on the composition 70:30 with $2 \% \mathrm{NaOH}$ concentration was 8,005 $\mathrm{kJ} / \mathrm{m}^{2}$.
\end{abstract}

Keywords: bagasse, epoxy, impact strength, alkali treatment

\section{Pendahuluan}

Dewasa ini, penggunaan bahan polimer di dunia industri berkembang dengan sangat pesat. Hal ini dikarenakan bahan polimer memiliki sifat ringan, murah, tahan korosi, dan temperatur pemrosesannya yang relatif rendah bila dibandingkan dengan bahan logam ataupun bahan keramik. Pada umumnya bahan polimer ini dicampurkan dengan bahan lain untuk memperoleh sifat yang lebih baik, yang dikenal sebagai bahan komposit. Pada dasarnya material komposit merupakan gabungan dari dua atau lebih material yang berbeda menjadi suatu bentuk unit mikroskopik, yang terbuat dari bermacam-macam kombinasi sifat atau gabungan antara serat dan matrik. Saat ini bahan komposit yang diperkuat dengan serat merupakan bahan teknik yang banyak digunakan karena kekuatan dan kekakuan spesifik yang jauh di atas bahan teknik pada umumnya [4].

Tebu merupakan salah satu komoditi pertanian yang mengandung unsur lignoselulosa sehingga berpotensi sebagai bahan baku pembuatan papan partikel.. Ampas tebu merupakan sumber alternatif utama dalam pembuatan papan partikel [11]. Berdasarkan inventarisasi beberapa sumber utama bio-based composite keberadaan bagase mencapai 75 juta ton berdasarkan berat keringnya [9]. Ampas tebu yang memiliki kandungan kimia yang terdiri dari selulosa (26-43\%), hemiselulosa (17-23\%), pentosan (20-33\%), dan lignin (13-22\%) [8], berpotensi menjadi bahan baku pengisi pembuatan komposit.

Berdasarkan hasil penelitian Sudhir Kumar dan Chandan Datta [5], sifat mekanik komposit epoksi dengan ampas tebu tanpa perlakuan dengan rasio epoksi/ ampas tebu 70:30 memiliki hasil Tensile Strength 9,87 MPa, Flexural Strength 26,78 $\mathrm{MPa}$, dan Impact Strength $6,67 \mathrm{~kJ} / \mathrm{m}^{2}$.

Pada komposit polimer berpenguat serat alam, sifat antar muka matriks dan serat perlu diperhatikan. Hal ini berkaitan dengan kompatibilitas antara serat dengan matriks dan sifat hidrofilik serat. Alkalisasi adalah salah satu cara modifikasi serat alam untuk meningkatkan kompatibilitas matriks-serat. Dari penelitian Kifli Umar [10], diperoleh pengaruh perlakuan permukaan serat dengan $\mathrm{NaOH}$ dapat meningkatkan kekuatan mekanis dari komposit.

Tujuan dari penelitian ini adalah untuk mengetahui pengaruh perlakuan alkali serat dan 
komposisi terhadap sifat kekuatan bentur komposit epoksi berpengisi serat ampas tebu.

\section{Teori}

\section{Komposit}

Bahan komposit menunjukkan artian bahwa dua atau lebih material digabung pada skala makroskopis untuk membentuk material ketiga yang berbeda. Material-material yang berbeda dapat digabung dalam skala mikroskopis seperti memadukan logam. Bila suatu komposit dirancang dengan baik maka akan memberikan kualitas yang bagus daripada komponen atau konstituen penyusunnya. Beberapa sifat yang dapat dikembangkan dengan membentuk bahan komposit yaitu : kekuatan (strength), kekakuan (stiffness), tahanan korosi (corrosion resistance), tahanan aus (wear resistance), daya pikat (attractiveness), berat, perioda lelah (fatigue life), sifat ketergantungan suhu (temperaturedependent behavior), insulasi termal, konduktivitas termal, dan insulasi akustik (acoustical insulation) [4].

\section{Resin epoksi}

Resin epoksi mengandung struktur epoksi atau oxirene. Resin ini berbentuk cairan kental atau hampir padat, yang digunakan untuk material ketika hendak dikeraskan. Resin epoksi jika direaksikan dengan hardener yang akan membentuk polimer crosslink. Hardener untuk sistem curing pada temperatur ruang dengan resin epoksi pada umumnya adalah senyawa poliamid yang terdiri dari dua atau lebih grup amina. Curing time sistem epoksi bergantung pada kereaktifan atom hidrogen dalam senyawa amina. Epoksi memiliki ketahanan korosi yang lebih baik dari pada polyester pada keadaan basah, namun tidak tahan terhadap asam. Epoksi memiliki sifat mekanik, listrik, kestabilan dimensi dan penahan panas yang baik [2].

\section{Serat Ampas Tebu}

Ampas tebu merupakan limbah berserat dari batang tebu setelah melalui proses penghancuran dan ekstraksi. Ampas tebu, seperti halnya biomassa yang lain, terdiri dari tiga penyusun utama, yaitu selulosa, hemiselulosa, lignin dan sisanya unsur penyusun lainnya. Ampas tebu sebagian besar mengandung lignocellulose. Panjang seratnya antara 1,7-2 mm dengan diameter sekitar 20 mikro, sehingga ampas tebu ini dapat memenuhi persyaratan untuk diolah menjadi papan-papan buatan. Bagas mengandung air $48-52 \%$, gula rata-rata 3,3\% dan serat rata-rata $47,7 \%$. Serat bagas tidak dapat larut dalam air dan sebagian besar terdiri dari selulosa, pentosan dan lignin [1].
Adapun struktur pembentuk serat ampas tebu terdiri dari Selulosa, Hemiselulosa, Pentosan dan Lignin yang komposisinya pada Tabel 2.1.

Tabel 1. Struktur Pembentuk Ampas Tebu [6]

\begin{tabular}{|l|l|l|}
\hline No. & Komponen & \% Berat Kering \\
\hline 1 & Selulosa & $26 \%-43 \%$ \\
2 & Hemiselulosa & $17-23 \%$ \\
3 & Pentosan & $20 \%-33 \%$ \\
4 & Lignin & $13 \%-22 \%$ \\
\hline
\end{tabular}

Dari komposis diatas serat ampas tebu berpotensi menjadi pengisi dalam komposit karena memiliki kadar selulosa yang tinggi.

\section{Alkalisasi Serat Ampas Tebu \\ Alkalisasi pada serat merupakan proses modifikasi permukaan serat dengan cara perendaman serat ke dalam basa alkali. Reaksi berikut menggambarkan proses yang terjadi saat perlakuan alkali pada serat:}

$$
\text { Fiber }-\mathrm{OH}+\mathrm{NaOH} \longrightarrow \text { Fiber-O-Na }{ }^{+}+\mathrm{H}_{2} \mathrm{O}
$$

Tujuan dari proses alkalisasi adalah mengurangi komponen penyusun serat yang kurang efektif dalam menentukan kekuatan antarmuka yaitu hemiselulosa, lignin atau pektin. Dengan pengurangan komponen lignin dan hemiselulosa, akan menghasilkan struktur permukaan serat yang lebih baik dan lebih mudah dibasahi oleh resin, sehingga menghasilkan mechanical interlocking yang lebih baik.[6].

\section{Metodologi \\ Bahan}

Epoksi diperoleh dari cabang PT. Justus Kimia Raya yang beralamat di Medan , dan ampas tebu diperoleh limbah dari pedagang minuman tebu didaerah sekitar kampus Universitas Sumatera Utara.

\section{Prosedur Penelitian}

Serat dipisahkan dari kulit ampas tebu dengan menggunakan tangan. Kemudian serat dicuci dengan air dan dikeringkan selama 3 hari di bawah sinar matahari.

\section{Alkalisasi Serat Ampas Tebu}

Serat ampas tebu direndam di dalam $\mathrm{NaOH}$ dengan konsentrasi $0 \%, 1 \%, 2 \&$, dan $3 \%$ selama 1 jam. Kemudian serat dicuci berulang kali dengan menggunakan air hingga $\mathrm{pH}$ 7-7,5 dengan menggunakan indicator $\mathrm{pH}$ universal. Serat dikeringkan didalam oven dengan suhu $120^{\circ} \mathrm{C}$ hingga berat serat konstan. 


\section{Pembuatan Partikel Serat Ampas Tebu}

Serat yang telah mengalami proses alkalisasi di giling kedalam ball mill hingga serat halus dan membentuk partikel. Partikel di ayak dengan ayakan dengan ukuran 50 mesh.

Proses Pembuatan Komposit Epoksi Berpengisi Ampas Tebu

Resin epoksi dan epoksi harderner disiapkan dengan rasio 3:2. Partikel serat ampas tebu dicampurkan dengan resin epoksi dengan rasio 100:0, 70:30, 60:40, dan 50:50 dan diaduk hingga merata. Komposit dituangkan ke dalam cetakan dan didiamkan hingga mengeras pada temperatur ruangan. Komposit kemudian diuji sesuai standar ASTM D 4812-11.

\section{Hasil dan Pembahasan}

\section{Pengaruh Komposisi dan Perlakuan Alkali terhadap Kekuatan Bentur Komposit Epoksi Berpengisi Ampas Tebu \\ Pengaruh komposi dan perlakuan alkali} pada serat ampas tebu terhadap kekuatan bentur komposit epoksi berpengisi serat ampas tebu diperlihatkan oleh gambar 1 berikut :

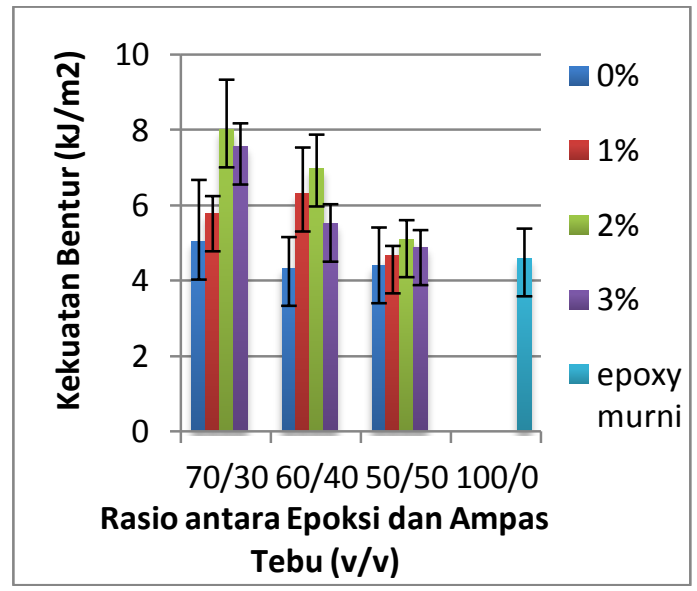

Gambar 1. Pengaruh Komposisi dan Perlakuan Alkali Terhadap Kekuatan Bentur Komposit Epoksi Berpengisi Serat Ampas Tebu

Pada gambar 1. diatas dapat dilihat bahwa kekuatan bentur maksimum dari komposit berada pada perbandingan komposisi 70:30 dan perlakuan alkali $2 \%$ sebesar $8,006 \mathrm{~kJ} / \mathrm{m}^{2}$, kekuatan bentur minimum pada perbandingan komposisi 60:40 dan 0\% alkali sebesar 2,335 $\mathrm{kJ} / \mathrm{m}^{2}$,serta kekuatan bentur dari epoksi murni sebesar $4,587 \mathrm{~kJ} / \mathrm{m}^{2}$. Kekuatan bentur material komposit berhubungan langsung dengan keseluruhan kekuatannya, yang mana sangat dipengaruhi oleh kekuatan ikatan antar fasa, matriks, dan sifat serat. Serat memegang peranan penting dalam ketahan bentur dari komposit, dimana serat berinteraksi dengan crack formation dalam matriks dan bertindak sebagai media stress transferring [7]. Penambahan rasio pengisi mengakibatkan berkurangnya kekuatan bentur komposit. Penurunan ini terjadi karena jumlah pengisi yang semakin besar mengakibatkan fasa matriks tidak mampu membasahi seluruh bagian permukaan serat secara sempurna.

Dalam penelitian ini, kekuatan bentur juga meningkat dengan perlakuan alkali. Peningkatan sifat-sifat mekanis pada komposit berpenguat serat yang mengalami perlakuan alkali pada permukaan serat menunjukkan fakta bahwa terjadi perbaikan karakteristik perekatan (adhesion) permukaan serat oleh perbaikan cacat alami dan topografi permukaan serat menjadi kasar. Selain itu pengaruh pelakuan kimia dan perebusan pada serat juga dapat membersihkan dan mengubah topografi permukaan serat, meningkatkan kekerasan permukaan serat sehingga dapat meningkatkan daya ikat interfacial antara serat ampas tebu dengan matriks/resin epoksi. Perubahan topografi permukaan serat yang kasar tersebut akan menghasilkan mechanical interlocking yang lebih baik dengan matrik [10].

\section{Bentuk Morfologi Permukaan}

Morfologi Permukaan dari komposit epoksi berpengisi serat ampas tebu diperlihakan oleh gambar 2 berikut :

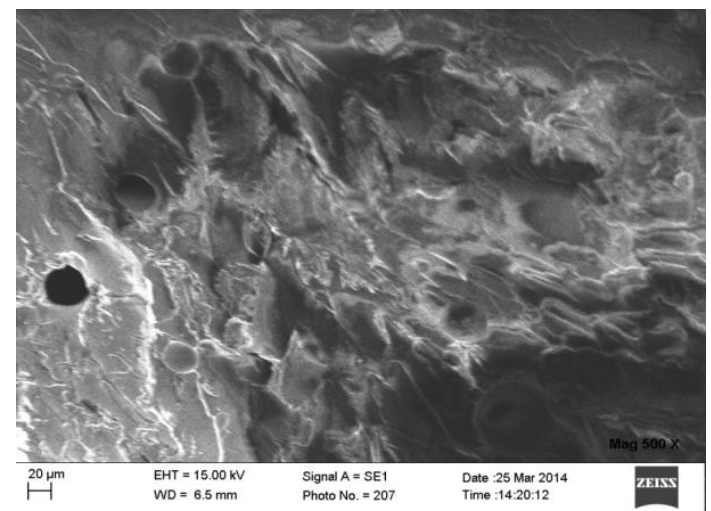

\section{Gambar 2. Bentuk Morfologi Permukaan}

Pada gambar 2. menunjukkan morfologi patahan uji bentur dengan perbesaran $500 \mathrm{x}$ dari komposit epoksi berpengisi serat ampas tebu $70: 30$ dan $2 \%$ alkali. Pada komposit berpengisi serat ampas tebu ini terjadi kegagalan yang didominasi oleh lepasnya ikatan antara serat dengan matriks yang disebut fiber pull out 


\section{Kesimpulan}

Dari hasil analisa uji kekuatan bentur, kekuatan bentur komposit epoksi - serat ampas tebu mampu meningkatkan kekuatan bentur epoksi murni, dengan nilai maksimum berada pada perbandingan komposisi 70:30 dan perlakuan alkali $2 \%$ sebesar $8,006 \mathrm{~kJ} / \mathrm{m}^{2}$, sedangkan kekuatan bentur epoksi sebesar $4,587 \mathrm{~kJ} / \mathrm{m}^{2}$

\section{Daftar Pustaka}

[1] Arsyad, F.T. "Pengaruh Proporsi Campuran Serbuk Kayu Gergajian dan Ampas Tebu Terhadap Kualitas Papan Partikel yang Dihasilkan". Tugas Akhir Sarjana Kehutanan. Institut Pertanian Bogor : Bogor, 2009.

[2] Darmansyah. "Evaluasi Sifat Fisik Dan Sifat Mekanik Material Komposit Serat/Resin Berbahan Dasar Serat Nata De Coco Dengan Penambahan Nanofiller". Tesis Magister Teknik. Universitas Indonesia : Depok, 2010.

[3] Ifannossa A A E, Hadi B K dan Kusni M, "Analisa Kekuatan Tarik Komposit Serat Bambu Laminat Helai dan Wooven yang Dibuat Dengan Metode Manufaktur Hand Lay-Up," Skripsi Program Sarjana Teknik ITB, Bandung, 2010.

[4] Jones R M, Mechanics of Composite Materials. Second Edition, (U.S.A: Taylor \& Francis, 1999).

[5] K.S. Sudhir, Datta C. "Thermomechanical Properties of Jute/Bagasse Hybrid Fibre Reinforced Epoxy Thermoset Composites". BioResources 4(4) 2009, 1455-1476.

[6] Maryanti B, Sonief AA, dan Wahyudi S. 2011." Pengaruh Alkalisasi Komposit Serat Kelapa-Poliester Terhadap Kekuatan Tarik". Jurnal Rekayasa Mesin Vol. 2, No.2 Tahun 2011 : 123-129. Universitas Brawijaya : Malang.

[7] Megat, M.H., Abdalla, F.H., Sapuan, M.S., Sahari, B.B., "Determination of Volume Fraction Values Of Filament Wound Glass and Carbon Fiber Reinforced Composites". ARPN Journal of Engineering and Applied Sciences Vol. 3, No.4. 2008.

[8] Nurwahyu Hidayati. "Pengaruh Penambahan Abu Ampas Tebu Terhadap Sifat Fisis dan Mekanis Batako". Tugas Akhir Sarjana Teknik. Universitas Sumatera Utara : Medan, 2010.

[9] Rowell, R.M. "The State of Art and Future Development of Bio-Based Composite Science and Technology Towards the $21^{\text {st }}$ Century". Proceedings of The Fourth Pasific Rim Bio-Based Composites
Symposium. 2-5 November 1998 : Bogor, 1998.

[10] Umar, K.,dan Abbas, S., "Pengaruh Perlakuan Permukaan Serat Terhadap Sifat Mekanik Komposit Gnetum GnemonEpoxy Resin", Jurnal Teknologi, Media Perspektif : Samarinda, 2011.

[11] Walker. J. C. F. "Primary Wood Processing, Principles and Practice". Chapman \& Hall : London, 1993. 